\title{
Selection of recruitment methods in construction organizations
}

\author{
Irina Reshetnikova ${ }^{1}$, Natalia Zotkina ${ }^{1 *}$ and Miroslava Gusarova ${ }^{1}$ \\ ${ }^{1}$ Tyumen Industrial University, Volodarskogo str., 38, Tyumen, 625000, Russia
}

\begin{abstract}
There are methods for determining the quantitative and qualitative need for labor in the paper. The methods of recruitment are analyzed. Classification of methods of recruiting is given. Their advantages and disadvantages are revealed. The paper presents the results of a study on modern methods of recruiting personnel used by construction organizations in Tyumen.
\end{abstract}

\section{Introduction}

The effective recruitment reduces the risk of the introduction of the organizational environment of poor-quality workforce. To ensure the successful implementation of the process necessary to improve the decision-making procedure to attract staff. The involvement of staff begins after determining the quantitative and qualitative requirements for a particular workforce and the analysis of the recruitment method. The correct method of recruiting will be ensured by effective recruitment.

\section{Materials and Methods}

The number of necessary candidates can be determined, first, with the help of the recruitment efficiency pyramid. It shows the ratio of the number of candidates that an organization should be interested in this work to the required number of new employees. This pyramid is based on empirical data on similar campaigns. An example of such a pyramid is shown in Fig. 1.

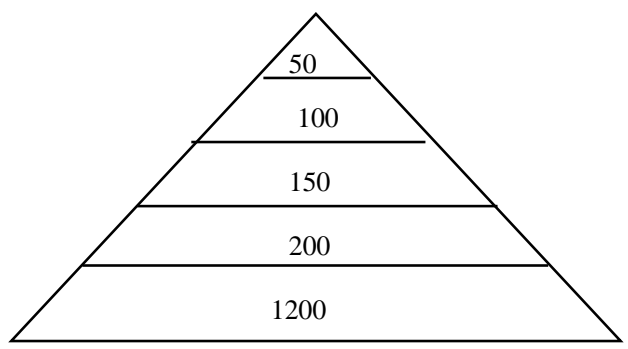

Fig. 1. Recruitment efficiency pyramid

*Corresponding author: a.copytowa@yandex.ru 
On the other hand, the number of necessary candidates can be calculated based on probability theory. The normal curve or the Gaussian curve is shown in Fig. 2

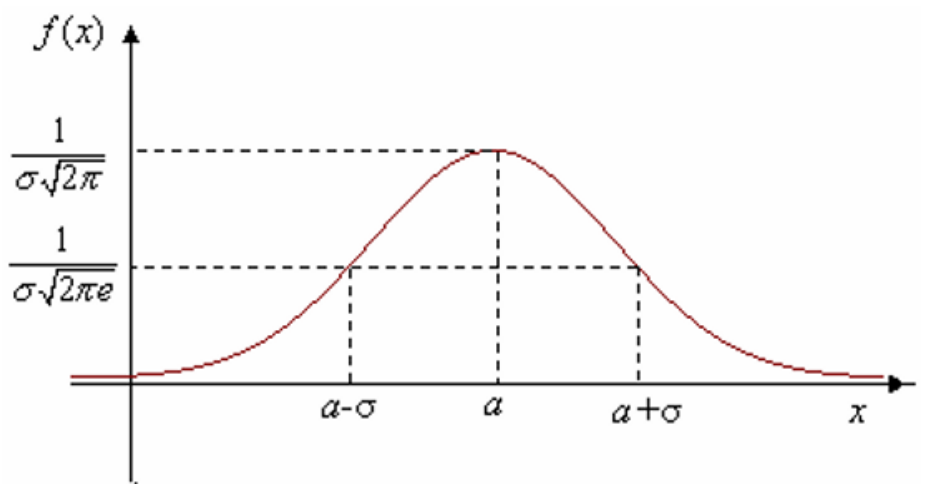

Fig. 2. The normal curve (the Gaussian curve)

Taking as a basis the normal distribution curve $\mathrm{f}(\mathrm{x})$ (normal curve or Gauss curve), it is possible to calculate the required number of candidates (or a fraction of the candidates) required for subsequent selection. The number of necessary workers can be found by the formula (1).

$$
F(x)=\frac{1}{2}+\Phi\left(\frac{x-a}{\sigma}\right)
$$

where $\Phi(\mathrm{x})$ is expressed in terms of the Laplace function by formula

$$
\Phi(x)=\frac{1}{\sqrt{2 \pi}} \int_{0}^{x} e^{\frac{-t^{2}}{2}} d t
$$

In these formulas, $\mathrm{x}$ will indicate the likelihood that a person would, with the quality of the environment of employees, exceeding the average by $x$-a. The calculated share and the number of employees involved, necessary for the organization to be able to select a candidate with qualities exceeding the average for $\mathrm{x}$.

The selection of employees can be from external or internal sources. Each of them has both disadvantages and advantages, which are described by many authors $[1,4,5,7,10,11$, $12]$.

The external methods of recruitment include the following: : the expectation of the people who accidentally entered the organization in search of work, advertisements in newspapers, announcements on $\mathrm{TV}$, radio, interviewing relatives and friends, Internet recruiting, direct recruitment of graduates, contacting recruitment agencies, attracting headhunters.

The dependence of methods of recruitment and market conditions there has been studied by many authors. However, at the enterprises of the construction industry, an approach to the selection of recruitment methods has not yet been worked out.

When choosing recruitment methods, one must be guided by their strengths and weaknesses, choosing the most suitable method for each vacancy separately.

A sociological study was conducted to determine the methods of attracting personnel used by the construction organizations of Tyumen and to compare their advantages and 
disadvantages.

During the research methods of questioning, interviewing, statistical processing of results were used.

The construction organization of Tyumen was an experimental base of the research.

The study was conducted in 28 organizations in Tyumen. Randomization was provided by a mechanical sample of construction organizations, arranged in alphabetical order.

The criterion for choosing objects was a sign of professional belonging to the heads of personnel services (heads of personnel departments, personnel managers, etc.).

Subjects were offered the author's questionnaire, aimed at:

- identification of sources and methods of recruitment and selection of personnel used in construction firms

- demand on the labor market by construction firms

- evaluation of the importance of qualities in the selection of personnel

Questions were asked separately for employees and employees.

The study was conducted from June to August 2017.

To process the first question, a fraction of the frequency of mention of each source was found separately for large, medium and small enterprises.

The results of the answers to the question, the purpose of which was to find out the methods of personnel selection, were processed as follows: the first mention was assigned 2 points, and the subsequent one - one point. By the sum of points the popularity of methods was determined: the greatest number of points means the greatest popularity. The frequency of use of each method by enterprises was also found.

To interpret the results of the answers to the questions in the second section, the following processing was performed:

1. The spontaneous mention of personal and professional qualities of applicants was given the highest score - 10, other qualities were considered in accordance with the assessments given by respondents.

2. The quality of the assessments was checked for the equiprobability of its values. The criterion of the rating was the scatter coefficient equal to the ratio of the maximum to the minimum.

3. Depending on the scatter factor, the need for a method for processing (improving) estimates:

- With a spreading factor of less than 1.3, the quality of the estimates is considered satisfactory, there are no random values in it;

- With a spreading factor less than 2 and greater than 1.3, estimates are processed using the limit value method;

- With a spreading factor greater than 2, estimates are processed by the method of calculating the relative mean square error.

4. We calculated the final estimate, equal to the weighted average for each of the proposed qualities.

The reasonableness and reliability of the results are provided by carrying out the research under strictly controlled conditions. And also using a set of theoretical and empirical research methods that are consistent with the goals and objectives of the work and the representativeness of the samples.

\section{Results}

According to the study, it was revealed that external recruitment methods depend on many factors. Each method has both advantages and disadvantages.

The main advantages and disadvantages of recruitment methods are presented by the author in Table 1. 
Table 1. Comparison of recruitment methods

\begin{tabular}{|c|c|c|}
\hline Methods & Advantages & Disadvantages \\
\hline $\begin{array}{l}\text { Placement of } \\
\text { announcements in } \\
\text { newspapers }\end{array}$ & $\begin{array}{l}\text { Low costs } \\
\text { targeting } \\
\text { Accessibility for all potential } \\
\text { applicants }\end{array}$ & $\begin{array}{l}\text { A large number of competing } \\
\text { advertisements }\end{array}$ \\
\hline $\begin{array}{l}\text { Placement of } \\
\text { announcements } \\
\text { on } \mathrm{TV} \text {, radio }\end{array}$ & $\begin{array}{l}\text { Possible colorful advertisement } \\
\text { serving }\end{array}$ & $\begin{array}{l}\text { Relative expensiveness } \\
\text { Low targeting }\end{array}$ \\
\hline $\begin{array}{l}\text { Direct } \\
\text { recruitment of } \\
\text { graduates }\end{array}$ & $\begin{array}{l}\text { "cheapness" of graduates } \\
\text { the enthusiasm of "young blood" } \\
\text { current knowledge }\end{array}$ & $\begin{array}{l}\text { lack of work experience of } \\
\text { applicants }\end{array}$ \\
\hline Internet recruiting & $\begin{array}{l}\text { Low costs } \\
\text { Easy selection } \\
\text { A large number of applicants }\end{array}$ & $\begin{array}{l}\text { Underdevelopment of Internet } \\
\text { culture among the older population }\end{array}$ \\
\hline $\begin{array}{l}\text { Contacting } \\
\text { recruiting } \\
\text { agencies }\end{array}$ & $\begin{array}{l}\text { Short time costs } \\
\text { Professional selection }\end{array}$ & $\begin{array}{l}\text { High costs } \\
\text { Incompetence of recruiters in the } \\
\text { required professional sphere }\end{array}$ \\
\hline Headhunters & Recruitment hard-to-find specialist & $\begin{array}{l}\text { High costs } \\
\text { Slowness in carrying out the order } \\
\text { The possibility of disclosure of } \\
\text { confidential information } \\
\text { Incompetence of recruitment in the } \\
\text { required professional sphere }\end{array}$ \\
\hline
\end{tabular}

Thus, recruitment methods also depend on supply and demand in the labor market, and the company is faced with the question of whether to apply a particular method of recruitment. As a result of the research, the following results of using the methods of staff involvement, presented in Fig. 3, were also revealed.

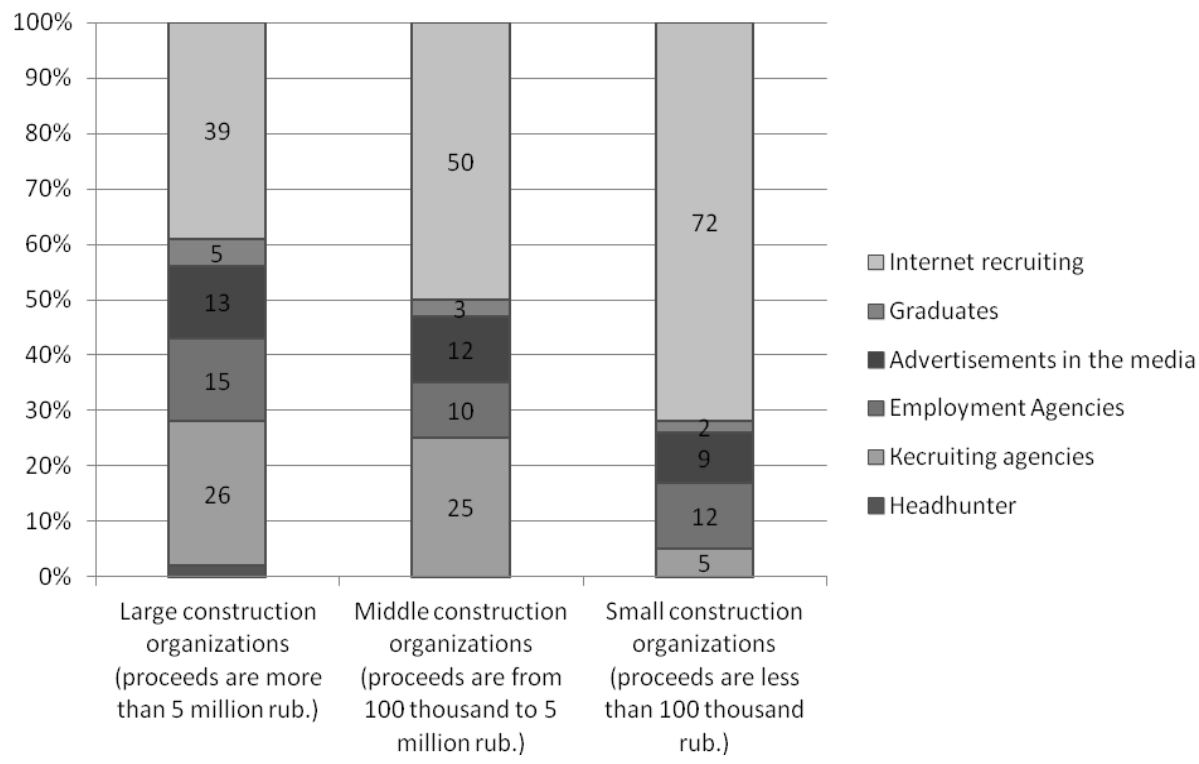

Fig. 3. Methods of recruitment used by construction organizations in Tyumen 
Aposteriori can be said that Internet recruiting is the method most combining the relationship between efficiency and price. It is most popular among all groups of enterprises. However, you can still say that its share varies inversely with the size of the enterprise. The services of recruitment agencies, which are quite expensive compared to other methods, are used mainly by large companies only - this share is $26 \%$.

Advertisements in the media, the method that most closely combines the ratio of efficiency and price, is popular with all groups of enterprises.

The proportion of graduates of educational institutions is a small percentage of all enterprises. Sometimes for employment of graduates high schools use original forms. The Youth Employment Exchange, the Tyumen City Employment Center and the Tyumen Youth Social and Business Center annually hold graduate fairs of various universities in Tyumen and the Tyumen Region. During the fairs, employers can perform the initial selection of young professionals, familiarize themselves with the bank of these applicants for the claimed specialties. No construction organization recruits people who come in by chance. Only large construction companies use headhunters for recruiting.

\section{Discussion}

If the demand for labor resources exceeds the supply to a large extent, then it is very difficult for an enterprise to find the right specialist. Then the enterprise uses such methods of recruitment, as the involvement of headhunters or appeals to recruiting agencies with the request to find the right specialist.

If the demand for labor resources exceeds the supply to a small extent, then the enterprise can apply to educational institutions in order to immediately recruit the most liked students from there. Another way is to apply to employment agencies. The third way is to interview relatives and friends who may know a suitable specialist. An employer enterprise can also look for an employee looking through a resume, which is placed in large numbers on free Internet sites specializing in job search. Most often, construction organizations use active methods to attract staff.

Given the excessive supply of labor resources, a situation arises when construction organizations use passive methods of recruiting staff. If the supply of labor resources is not much higher than the demand for them, then the enterprises usually place various kinds of announcements about the vacant place and wait for the people who are seeking work to respond to them. Such ads can be placed in newspapers (conventional and specialized), on radio, on television and on Internet sites, as well as conventional advertising or, more appropriately, specialized ones. In the event that the supply of labor resources is many times greater than the demand for them, the enterprise can simply expect people who accidentally entered the organization in search of work. Also, the choice of recruiting method depends on the size of the company and its financial position. In the future it is planned to investigate additional factors that influence the choice of recruiting methods, as well as the study of new methods of recruiting.

\section{Conclusion}

Thus, it is possible to distinguish various methods of recruitment. The most popular methods are: use of the Internet, placement of ads and recourse to recruiting companies. Each method has both positive and negative sides. Therefore, the choice of recruitment method should be carried out, mainly, depending on the labor market situation and depending on the size of the company. 


\section{References}

1. N. Zotkina, M. Gusarova, A. Kopytova, Advances in Intelligent Systems and Computing 692, 1204-1213 (2018) DOI: 10.1007/978-3-319-70987-1_129

2. A. Kopytova, Procedia Engineering 165, 1132 (2016) DOI: 10.1016/j.proeng.2016.11.830

3. A. Kopytova, MATEC Web of Conferences, 106, 08056 (2017) DOI: $10.1051 /$ matecconf/201710608056

4. N. Zotkina, S. Bardasov, M. Gusarova, A. Kopytova, MATEC Web of Conferences, 106, 08050 (2017) DOI: 10.1051/matecconf/201710608050

5. K. Pykhtin, T. Simankina, V. Sharmanov, A. Kopytova, IOP Conference Series: Earth and Environmental Science, 90 (1), 012065 (2017) DOI: 10.1088/1755$1315 / 90 / 1 / 012065$

6. V. Lezier, M. Gusarova, A. Kopytova, IOP Conference Series: Earth and Environmental Science, 90 (1), 012034 (2017) DOI: 10.1088/1755-1315/90/1/012034

7. A. Minnullina, R. Abdrazakov, Advances in Intelligent Systems and Computing 692, 1224-1233 (2018) DOI: 10.1007/978-3-319-70987-1_131

8. A.V. Kopytova, Exchange of intellectual property 3 (XIV), 31-37 (2015)

9. V. Lezier, M. Gusarova, A. Kopytova, IOP Conference Series: Earth and Environmental Science, 90 (1), 012069 (2017) DOI: 10.1088/1755-1315/90/1/012069

10. A. Mottaeva, A. Minnullina, IOP Conference Series: Earth and Environmental Science, 90 (1), 012123 (2017) DOI: 10.1088/1755-1315/90/1/012123

11. M. Gravit, O. Zybina, A. Vaititckii, A. Kopytova, IOP Conference Series: Earth and Environmental Science, 90 (1), 012103 (2017) DOI: 10.1088/1755-1315/90/1/012103

12. N. Zotkina, A. Kopytova, M. Zenkina, O. Zhigunova, MATEC Web of Conferences, 106, 08058 (2017) DOI: 10.1051/matecconf/201710608058

13. Fedorov, M., Matys, E., Kopytova, A. E3S Web of Conferences, 33, 03054 (2018) DOI: $10.1051 / \mathrm{e} 3$ sconf $/ 20183303054$ 